\title{
Maria Bonita nas Ciências :: um projeto para divulgar Ciências às meninas de escolas públicas
}

\author{
Glaucia M. M. Campos ${ }^{\Phi}$, Ana Cecília M. de Melo $^{\Psi}$ \\ ${ }^{1}$ Curso de Ciência da Computação ${ }^{\Phi}$, Curso de Ciência e Tecnologia ${ }^{\Psi}$ \\ Universidade do Estado do Rio Grande do Norte (UERN) \\ Natal-RN, Brasil \\ glauciamelissa@uern.br, ceciliamartinianoealu.uern.br
}

\begin{abstract}
The unequal representation of women in the areas of Science, Technology and Engineering remains a challenge. The untapped potential of brilliant women begins in childhood and continues in universities. In the workplace, women suffer from competition, lower wages and sexual harassment. Therefore, expanding women's participation in the sciences should be a constant concern. The Maria Bonita in Sciences project aims to arouse the interest of high school girls in science, especially technology courses. The target audience is for girls from public schools in the north zone of Natal/RN. The project's actions consist of short courses, workshops and lectures with professionals in the field.
\end{abstract}

Resumo. A representação desigual das mulheres nas áreas de Ciência, Tecnologia e Engenharia continua sendo um desafio. O potencial inexplorado de mulheres brilhantes começa na infância e continua nas universidades. No ambiente de trabalho, as mulheres sofrem com a competição, salários mais baixos e assédio sexual. Portanto, ampliar a participação de mulheres nas ciências deve ser uma preocupação constante. O projeto Maria Bonita nas Ciências objetiva despertar o interesse das meninas estudantes de ensino médio para as ciências, em especial, os cursos de tecnologia. O público-alvo está nas meninas de escolas públicas da zona norte de Natal/RN. As ações do projeto consistem em minicursos, oficinas e palestras com profissionais da área.

\section{Introdução}

Inicialmente, a participação das mulheres no desenvolvimento da ciência foi bastante expressiva. É possível destacar Ada Lovelace com a criação do primeiro algoritmo e Grace Hopper com o primeiro compilador para o computador Mark I e os termos bug/debug [Alencar et al. 2019]. Porém, mesmo com essa participação significativa, percebe-se atualmente uma representação desigual das mulheres nas carreiras científicas, mais especificamente nos campos da Ciência, Tecnologia, Engenharia e Matemática (STEM).

De acordo com o relatório da UNESCO [UNESCO 2018], meninos e meninas possuem o mesmo interesse e habilidades nessas áreas até a educação básica, o que muda com a adolescência. Com isso, somente $30 \%$ da população estudantil mundial de mulheres escolhe campos de estudo relacionados à STEM. O Brasil não apresenta comportamento diferente, principalmente para áreas tecnológicas. Segundo os dados do Instituto Nacional de Estudos e Pesquisas Educacionais (INEP), o número de cursos de 
computação cresceu $586 \%$ nos últimos 24 anos, contudo, o percentual de mulheres matriculadas nesses cursos diminuiu de 34,8\% para 15,5\% [Andrade 2019]. Nos cursos de Ciência da Computação e Ciência e Tecnologia da Universidade do Estado do Rio Grande do Norte (UERN), embora não tenha sido feito nenhuma pesquisa, é perceptível nas salas de aula que o número de meninas é reduzido, principalmente nos períodos mais avançados. Esse cenário representa o reflexo do desencorajamento provocado nas mulheres ao longo do tempo e por diversos seguimentos da sociedade que, pelo senso comum, rotulam algumas carreiras como masculinas.

Para reverter este quadro, é necessário descontruir muitas ideias. E isso deve começar com os brinquedos e as brincadeiras que separam meninos de meninas ainda na infância. Para o público mais jovem, existem outros desafios [Ferreira et al. 2019]: (i) é preciso aproximar as meninas do ensino básico e médio de áreas mais tecnológicas, desmistificando a ideia de que se trata de áreas masculinas; (ii) é necessário incentivar meninas que frequentam esses cursos a concluírem seus estudos; (iii) é fundamental manter o incentivo a mulheres que estão no mercado de trabalho.

Diversas iniciativas vêm sendo conduzidas para enfrentar esses desafios. No cenário internacional, temos a discussão sobre o empoderamento feminino por meio de tecnologias digitais como parte do conjunto de ações da Agenda 2030 para o Desenvolvimento Sustentável [ONU 2015]; o Dia Internacional de Mulheres e Meninas na Ciência [UNESCO 2020a] e o Prêmio Internacional L'Oréal-UNESCO Para Mulheres na Ciência [UNESCO 2020b]. Diversos países também têm investido em programas de verão gratuítos a fim de recrutar meninas do ensino médio para a Ciência da Computação [Burge et al. 2013] [Pollock et al. 2004], sendo alguns desses programas incentivos para áreas específicas dentro da Computação, como Inteligência Artificial [Vachovsky et al. 2016]. No cenário nacional, o Programa Meninas Digitais, da Sociedade Brasileira da Computação (SBC) [SBC 2020], tem como objetivo divulgar a área da Computação e suas tecnologias para meninas do ensino médio através de iniciativas locais. Mesmo com iniciativas como essas, as discussões sobre a desigualdade de gênero nas ciências e tecnologias devem permanecer, assim como novas ações devem ser implantadas em diferentes locais [ONU 2020].

Este artigo apresenta uma experiência promovida no contexto do projeto Maria Bonita nas Ciências que tem como objetivo principal despertar o interesse das meninas de escolas públicas do ensino médio para as Ciências, em especial para os cursos direcionados à tecnologia. Essas escolas estão concentradas na zona norte de Natal/RN, uma região considerada economicamente mais carente. A experiência consiste na realização de minicursos, exibição de filmes, oficinas e palestras com profissionais da área.

As seções deste artigo estão organizadas da seguinte forma: na Seção 2, constam informações sobre o projeto; a Seção 3 descreve a metodologia adotada para a execução do projeto; a Seção 4 reporta os relatos de experiência; e, a Seção 5 discorre sobre as considerações finais.

\section{O projeto Maria Bonita nas Ciências}

O projeto Maria Bonita nas Ciências é uma iniciativa dos cursos de Ciência da Computação e Ciência e Tecnologia, Campus de Natal, da Universidade do Estado do Rio Grande do Norte (UERN). Em 2019, o projeto foi cadastrado na universidade como 
projeto de extensão e recebeu o apoio financeiro do Programa Institucional de Bolsa de Extensão (PIBEX 2019), edital $n^{o}$ 006/2019 - PROEX/UERN. Também em 2019, o Maria Bonita nas Ciências foi cadastrado como projeto parceiro do Programa Meninas Digitais.

O nome do projeto é inspirado na figura feminina do cangaço, Maria Bonita, considerada por muitos como uma mulher nordestina forte, destemida e com caráter predominante. A literatura indica que, antes de entrar para o cangaço, Maria Gomes de Oliveira (seu nome verdadeiro) era uma mulher infeliz e insatisfeita com a sua vida. Ao conhecer o cangaço, apaixonou-se por Lampião, tornando-se a primeira mulher a acompanhar o bando, por livre e espontânea vontade, sendo considerada, nesse aspecto, uma mulher empoderada [Negreiros 2018].

A relação nome do projeto e os seus objetivos de empoderamento feminino nas ciências precisava de um símbolo que representasse a causa. Após a formação da equipe de trabalho, foi criada a logo do projeto que pode ser visualizada na Figura 1. Posteriormente, foram criadas as redes sociais do projeto (instagram - @ maria.bonita.nas.ciencias e facebook - Maria Bonita), essenciais para a divulgação dos nossos objetivos e ações.

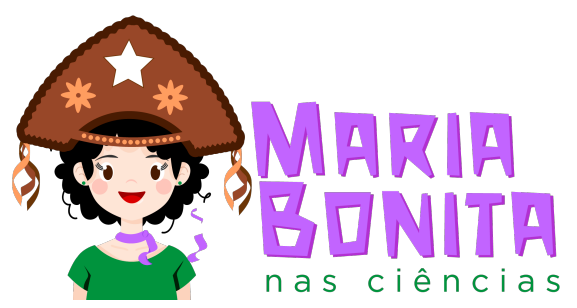

Figura 1. Logo do projeto Maria Bonita nas Ciências.

\section{Metodologia}

O projeto Maria Bonita nas Ciências começou as suas atividades em 2019, sendo a primeira turma realizada no período de agosto à novembro. Durante esse período, o projeto contou com o apoio de 15 pessoas, sendo 1 aluna bolsista, 8 alunas voluntárias, 4 meninas externas (à instituição UERN) voluntárias e 2 professoras coordenadoras.

Para a primeira turma, foram selecionadas 3 escolas públicas estaduais da zona norte, que ficam localizadas nas proximidades do Campus de Natal: Escola Estadual Professora Dulce Wanderley, Escola Estadual Professor Josino Macedo e Escola Estadual Peregrino Junior. Não consideramos o tamanho em dimensão, o número de alunas no ensino médio e nem mesmo o turno de realização das aulas presenciais como critérios para a escolha das escolas. Apenas a localização, o interesse de seus gestores e a facilidade de conversar com as turmas foram considerados. Inicialmente, a equipe realizou visitas às escolas para a divulgação do projeto nas turmas do ensino médio. As meninas interessadas preencheram uma ficha de inscrição com os dados pessoais e algumas informações necessárias para conhecermos a realidade do público-alvo em termos de conhecimentos tecnológicos, o que contribuiu para a definição das atividades extensionistas. Embora a equipe tenha visitado apenas essas três escolas, a divulgação do projeto também foi realizada nos principais meios de comunicação da cidade (rádios, jornais televisivos e online, além de redes sociais), por intermédio do setor de comunicação do Campus de Natal. Ao final, aproximadamente 50 meninas de escolas públicas de Natal apresentaram 
interesse no projeto. Inicialmente, definimos o número de 30 participantes por turma do projeto. Porém, considerando que um bom número dessas meninas poderia desistir do projeto por diferentes razões, aceitamos todas as inscrições.

A experiência foi realizada aos sábados, no período da manhã, com encontros de aproximadamente 03 horas, nas dependências do Campus de Natal. Foram 13 encontros semanais, durante os 03 meses de projeto, com uma carga horária total de 40h. Todas as atividades foram concretizadas sem custos para as participantes. Ao final, foi emitido um certificado de participação para as meninas com o mínimo de frequência de $75 \%$.

A Tabela 1 apresenta as atividades do projeto que foram executadas: oficinas, cursos, filmes, mesa-redonda e palestras temáticas. Além da programação técnica, as ações de extensão foram estruturadas considerando diversos aspectos da vida feminina e das condições do público-alvo, porém, sem fugir da temática do projeto: a motivação e o incentivo através da divulgação das ciências para as alunas do ensino médio. As escolas selecionadas estão localizadas em uma região considerada economicamente mais carente de Natal (a zona norte). Muitas estudantes precisam contribuir financeiramente com os seus estudos, como por exemplo, a venda de produtos para a compra de passagens diárias de ônibus para o deslocamento até às escolas. Por este motivo, foram inseridas atividades como a oficina de sobremesas rápidas, além de palestras esclarecedoras sobre gravidez e doenças sexualmente transmíssiveis na adolescência.

Tabela 1. Programação do Maria Bonita nas Ciências - Turma I

\begin{tabular}{|c|l|c|}
\hline ID & \multicolumn{1}{|c|}{ ATIVIDADE } & CARGA HORÁRIA \\
\hline PL1 & $\begin{array}{l}\text { Palestra de abertura: "Ser mulher na contemporaneidade: a } \\
\text { dor e a delicia de ser o que é". }\end{array}$ & $03 \mathrm{~h}$ \\
\hline OF1 & Oficina: "Pensamento computacional usando Scratch". & $04 \mathrm{~h}$ \\
\hline SF1 & Sessão de filme: "Estrelas além do tempo". & $03 \mathrm{~h}$ \\
\hline MR1 & $\begin{array}{l}\text { Mesa redonda: "Percursos de luta: trajetória de mulheres no } \\
\text { mercado de trabalho". }\end{array}$ & $03 \mathrm{~h}$ \\
\hline CUR1 & Curso: "Programação em blocos". & $12 \mathrm{~h}$ \\
\hline OF2 & Oficina: "Fotografia de produtos com smartphones". & $03 \mathrm{~h}$ \\
\hline OF3 & Oficina: "Sobremesas rápidas". & $03 \mathrm{~h}$ \\
\hline MR2 & Curso: "Arduíno" & $06 \mathrm{~h}$ \\
\hline PL2/PL3 & $\begin{array}{l}\text { Palestras de encerramento: "Câncer de mama" e "Gravidez } \\
\text { na adolescência e doenças sexualmente transmissíveis". }\end{array}$ & $03 \mathrm{~h}$ \\
\hline
\end{tabular}

Em geral, as ações extensionistas foram conduzidas por alunas dos cursos de Ciência da Computação e Ciência e Tecnologia, além das meninas externas que fazem parte da equipe do projeto. Porém, para atividades como a palestra de abertura e a mesaredonda, mulheres profissionais com diferentes perfis (formação e atuação) foram convidadas a compartilharem suas experiências. Em sua maioria, essas mulheres são professoras universitárias de outras instituições de nível superior. Para mantermos as meninas motivadas com o projeto, criamos dinâmicas competitivas ao final dos cursos. Cada equipe foi avaliada por uma banca examinadora formada pelas alunas de graduação membros do projeto. Ao final, as três equipes com as melhores avaliações receberam brindes. 


\section{Avaliação do projeto}

Embora aproximadamente 50 meninas tenham demonstrado interesse ao preencherem a ficha de inscrição durante as visitas às escolas, apenas 30 alunas compareceram aos primeiros encontros do projeto. A primeira turma finalizou com 25 meninas, mas somente 20 delas obtiveram frequência mínima de 75\%. Após a última atividade do projeto, solicitamos a cada uma delas o preenchimento de um questionário avaliativo sobre as ações executadas durante o projeto. No total, foram coletados 25 questionários. A Tabela 2 lista as perguntas e opções de respostas contidas no questionário.

Tabela 2. Lista de perguntas e opções de respostas do questionário de avaliação

\begin{tabular}{|c|c|c|}
\hline No & PERGUNTA & OPÇÕES \\
\hline 1 & Você gostou do projeto? (marque 3 se você não tem uma opinião formada) & $\begin{array}{l}\text { (Achei U Ó) } 1(\text { ), } 2(\text { (), } 3(\text { ) } \\
\text { 4( (), (Amei) } 5(\text { () }\end{array}$ \\
\hline 2 & $\begin{array}{l}\text { Você sentiu, por qualquer motivo, dificuldade em acompanhar as atividades } \\
\text { que foram realizadas? (marque } 3 \text { se você não tem uma opinião formada) }\end{array}$ & $\begin{array}{c}\text { (Nenhuma) } 1(),() 2,() 3() \\
4(), \text { (Muita) } 5(\text { () }\end{array}$ \\
\hline 3 & $\begin{array}{l}\text { Oferecendo notas de } 1 \text { à } 5 \text {, quais foram as atividades que você mais gostou? } \\
\text { (marque } 3 \text { se você não tem uma opinião formada) }\end{array}$ & $\begin{array}{c}\text { (Achei U Ó) } 1(\text { ) }, 2(), 3(\text { ) } \\
4(\text { ), (Amei) } 5(\text { ) }\end{array}$ \\
\hline 4 & $\begin{array}{l}\text { Considerando a pergunta acima, pode nos contar os motivos pelos quais mais } \\
\text { gostou de uma atividade específica e os motivos por não ter gostado da } \\
\text { atividade? (por favor, faça para todas as atividades). }\end{array}$ & Aberta \\
\hline 5 & $\begin{array}{l}\text { Você recomendaria esse projeto para alguma amiga? (marque } 3 \text { se você não } \\
\text { tem uma opinião formada) }\end{array}$ & $\begin{array}{c}\text { (De jeito nenhum) } 1(), 2(), 3(), \\
4(),(\text { Claro que sim) } 5()\end{array}$ \\
\hline 6 & $\begin{array}{l}\text { O projeto foi melhor do que você esperava? (marque } 3 \text { se você não tem uma } \\
\text { opinião formada) }\end{array}$ & $\begin{array}{c}\text { (De jeito nenhum) } 1(), 2(), 3(), \\
4(),(\text { Com certeza) } 5()\end{array}$ \\
\hline 7 & $\begin{array}{l}\text { Depois desse projeto, você consegue se imaginar trabalhando com algo de } \\
\text { computação ou ciência e tecnologia? (marque } 3 \text { se você não tem uma opinião } \\
\text { formada) }\end{array}$ & $\begin{array}{c}\text { (De jeito nenhum) } 1(), 2(), 3(), \\
4(),(\text { Com certeza) } 5()\end{array}$ \\
\hline 8 & $\begin{array}{l}\text { O tempo do projeto ( } 3 \text { meses) foi muito longo? (marque } 3 \text { se você não tem } \\
\text { uma opinião formada) }\end{array}$ & $\begin{array}{c}\text { (De jeito nenhum) } 1(), 2(), 3(), \\
4(),(\text { Com certeza) } 5()\end{array}$ \\
\hline 9 & $\begin{array}{l}\text { O projeto seria mais proveitoso se fosse realizado em um intervalo de tempo } \\
\text { menor? (marque } 3 \text { se você não tem uma opinião formada) }\end{array}$ & $\begin{array}{c}\text { (De jeito nenhum) } 1(), 2(), 3(), \\
4(),(\text { Com certeza) } 5()\end{array}$ \\
\hline 10 & $\begin{array}{l}\text { Quais outras atividades (que não foram realizadas pelo projeto) vocês acham } \\
\text { interessante inserir para um nova turma do projeto? }\end{array}$ & Aberta \\
\hline
\end{tabular}

As perguntas 1 e 6 foram elaboradas com o objetivo de identificar o nível de satisfação das meninas quanto ao projeto e, consequentemente, se elas indicam o projeto a outras meninas que apresentem interesse em participar de novas turmas (pergunta 5). De acordo com as respostas, $68 \%$ das meninas afirmaram ter amado o projeto (nota 5) e os $32 \%$ restante atribuíram uma nota boa (nota 4). Embora todas elas tenham gostado das ações, $8 \%$ informaram que a execução do projeto não surpreendeu as suas expectativas (nota 2) e 16\% não souberam opinar (nota 3) pois não formaram uma avaliação prévia. Mesmo assim, 84\% das meninas indicam com certeza (nota 5) o projeto para outras meninas/amigas das escolas. A Figura 2 apresenta as respostas do questionário para as perguntas 1, 5 e 6, de acordo com as notas atribuídas. Como é possível observar na figura, as alunas não atribuíram nota mínima (nota 1) para nenhuma das 3 questões.

Mediante as perguntas 2 e 10, analisamos o nível de dificuldade das meninas durante as ações executadas e quais outras atividades podem ser inseridas na programação de uma nova turma. Como mostra a Figura 3,76\% das alunas (nota 1) não sentiram dificuldades em acompanhar as atividades que foram realizadas, o que corrobora com as informações inseridas na ficha de inscrição. No entanto, $12 \%$ delas não se sentiram completamente seguras em todas as atividades, e os outros $12 \%$ indicaram não ter uma opinião 


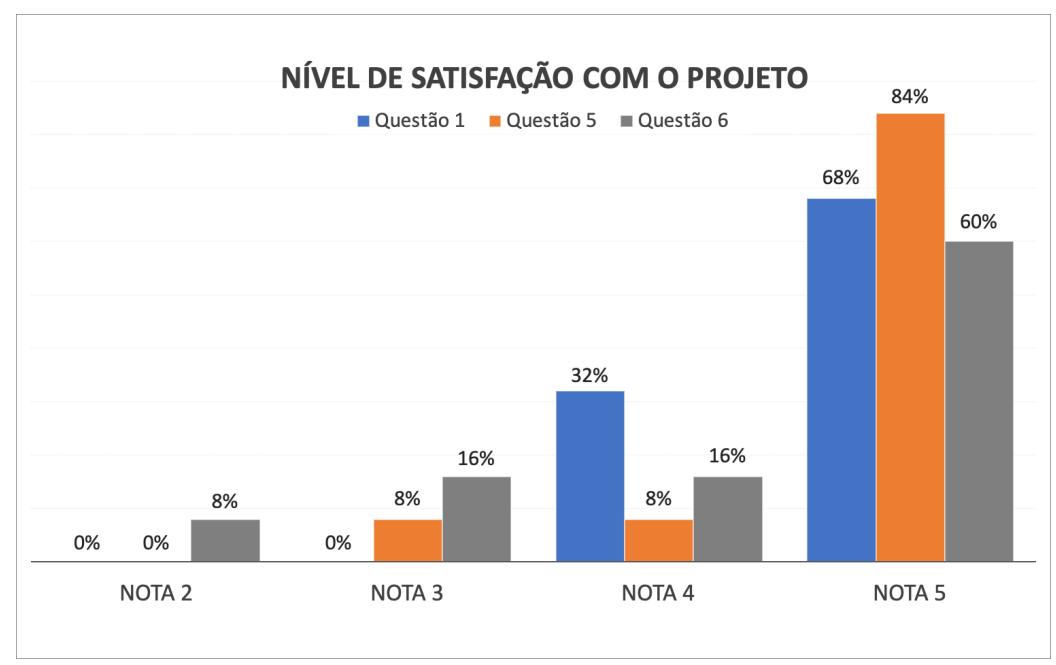

Figura 2. Nível de satisfação das meninas com o projeto.

formada (nota 3). Pelo que observamos durante a execução das ações, acreditamos que algumas meninas não conseguiram acompanhar todas as atividades e sentiram-se desconfortáveis em apresentar essa informação no questionário. A confirmação dessa suposição está nas respostas subjetivas da pergunta 10 , quando $12 \%$ das meninas sugeriram mais atividades nos computadores, por exemplo, cursos de softwares como o pacote office. As outras sugestões não estavam relacionadas diretamente com tecnologia, mas com questões pessoais: como morar sozinha, um espaço para apresentar os seus talentos e estudos direcionados ao ENEM.

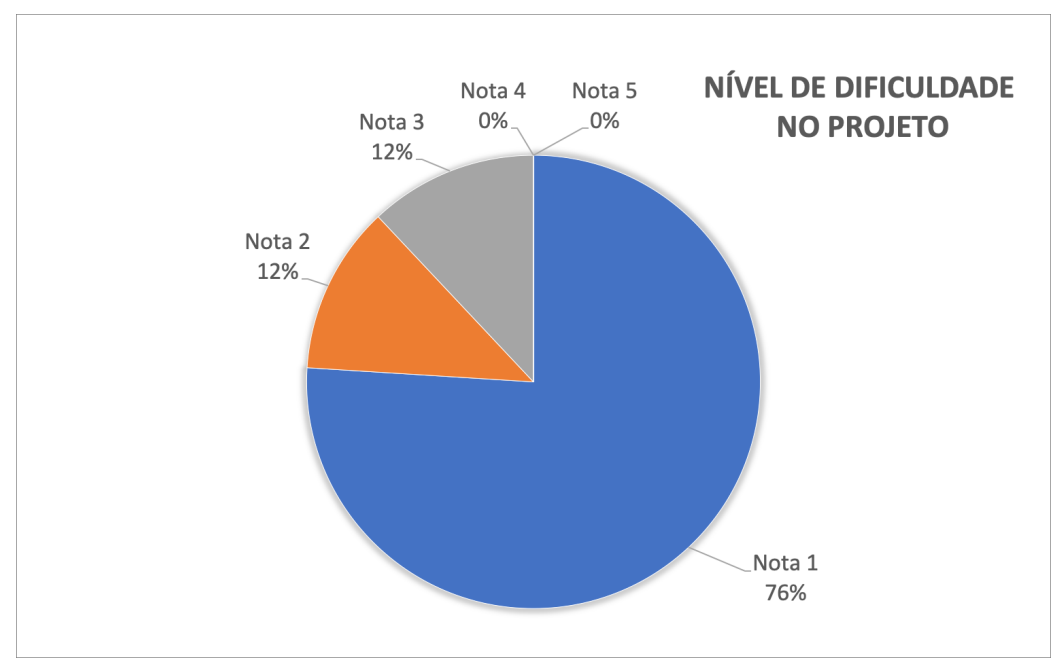

Figura 3. Nível de dificuldade das meninas com o projeto.

Além de identificar o nível de satisfação das meninas quanto ao projeto, também procuramos investigar as atividades que mais despertaram o interesse de cada uma delas. Através das perguntas 3 e 4, conseguimos obter as respostas para esses questionamentos. Como mostra a Figura 4, a sessão de filme: Estrelas além do tempo foi a atividade que elas mais gostaram (nota 5 - 84\% e nota 4 - 8\%), seguida pela oficina Sobremesas rápidas (nota $5-76 \%$ ). A atividade que menos despertou a atenção das meninas foi a oficina Fotografia de produtos com smartphones (nota 5 - 44\% e nota $4-32 \%$ ) e as justificati- 
vas foram semelhantes, muitas delas conheciam o conteúdo que foi abordado. Todas as outras atividades apresentaram avaliações semelhantes, com notas maiores (notas 4 e 5) equivalentes, estando as mudanças presentes no número de notas 3 (alunas não sabiam opinar pois não participaram da atividade) e notas 2 (alunas não gostaram da atividade).

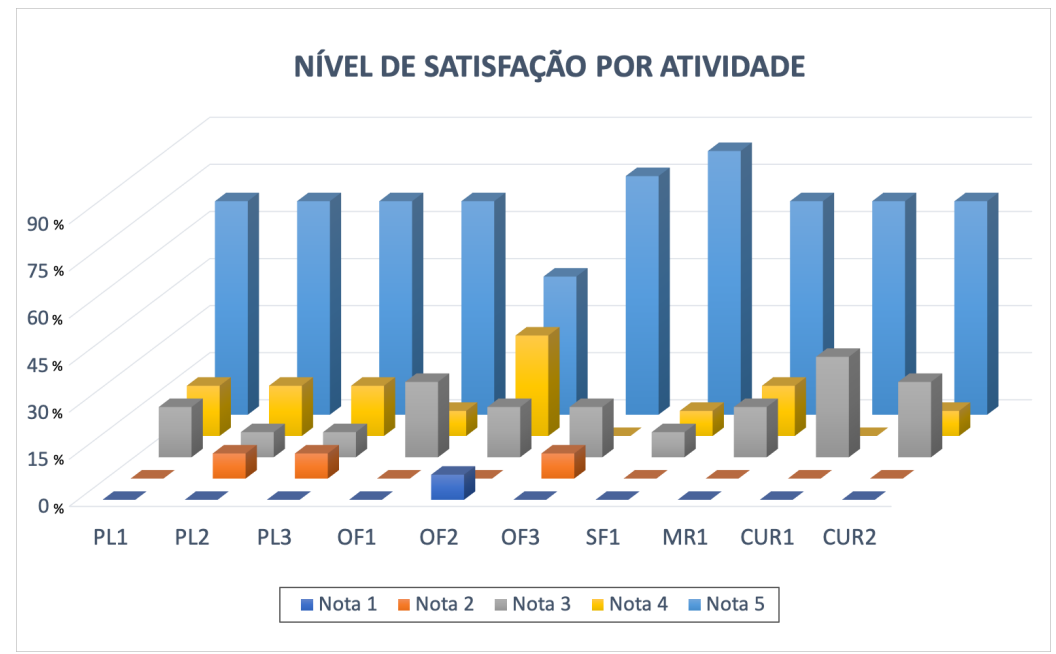

Figura 4. Nível de satisfação por atividade.

Pelas perguntas 8 e 9, procuramos avaliar o tempo de execução do projeto, com o propósito de identificar se o cronograma pode ter contribuído com algumas desistências. A Figura 5 mostra que menos de $50 \%$ das alunas (nota 1) estavam muito satisfeitas com o período de 3 meses, $20 \%$ delas apresentaram um nível de satisfação mais baixo (nota 2) e o restante não soube opinar ( $8 \%$ - nota 3$)$ ou declararam que o tempo poderia ter sido menor (24\% - nota 4). Somente após o início do projeto, observamos que essa duração de tempo poderia contribuir com a desmotivação, além da questão financeira das meninas (os custos com transportes).

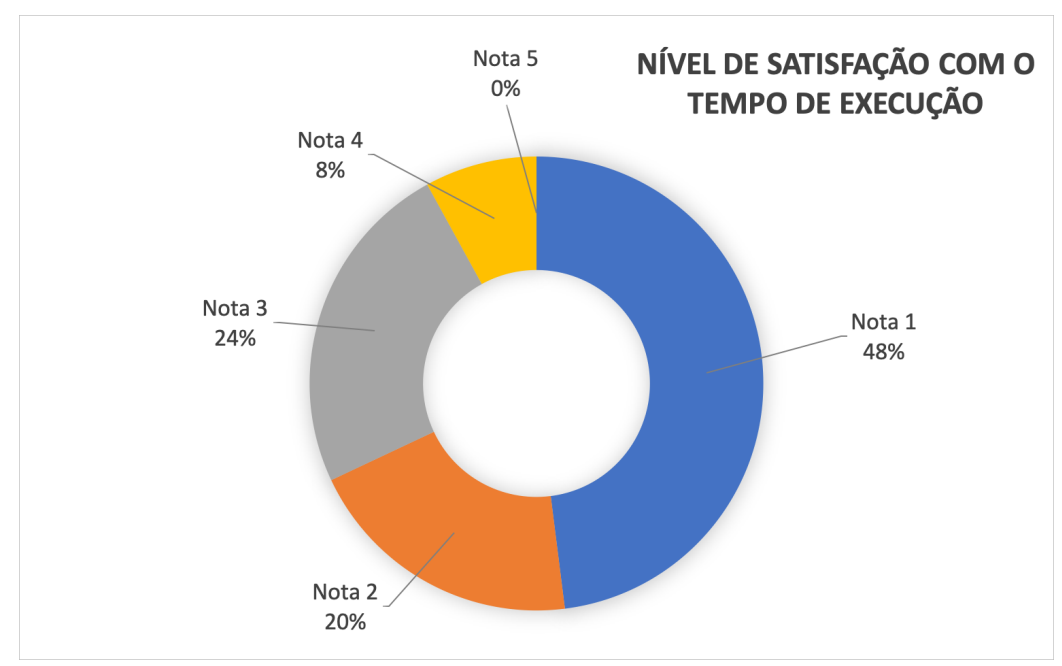

Figura 5. Nível de satisfação com o tempo de execução do projeto.

Por fim, buscamos verificar o interesse das meninas para a área de computação ou ciências e tecnologias após a finalização das atividades, sendo esse um dos focos principais do projeto. Ao final, observamos que $84 \%$ das meninas demonstraram interesse 
em trabalhar na área e desse percentual, $48 \%$ (nota 5) afirmaram com certeza e os outros $36 \%$ (nota 4) que possivelmente teriam interesse. Apenas $16 \%$ das meninas ainda não conseguem opinar sobre o assunto.

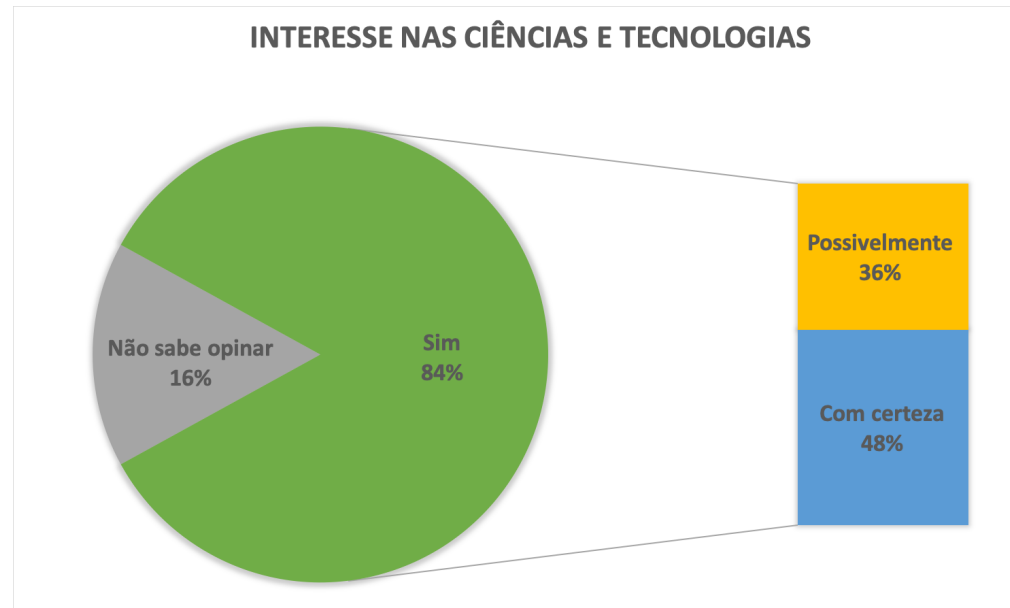

Figura 6. Interesse nas ciências e tecnologias.

\section{Considerações Finais}

Este artigo descreve um projeto de extensão voltado para as alunas do ensino médio, de escolas públicas da zona norte de Natal/RN. O projeto visa por objetivo despertar o interesse dessas meninas para as ciências, em especial para os cursos direcionados à tecnologia, desmestificando a ideia de que essas são áreas masculinas e, consequentemente, motivando novas entrantes nos cursos de Ciência da Computação e Ciência e Tecnologia da UERN - Campus de Natal.

Inicialmente, observou-se que o interesse em participar do projeto é muito alto, o que se deve a diferentes fatores: a própria temática que desperta curiosidade nas meninas; a gratuidade das atividades; a não-limitação do número de vagas inicial; a divulgação nas escolas feita pessoalmente pela coordenação do projeto e as alunas dos cursos de Ciência da Computação e Ciência e Tecnologia, além do excelente trabalho de divulgação na imprensa estadual intermediado pelo setor de comunicação do Campus de Natal.

Ao término da primeira turma do Maria Bonita nas Ciências, percebemos que o projeto teve impacto positivo para as meninas que participaram, o que foi comprovado durante a realização das atividades, assim como as respostas do questionário avaliativo. Com isso, destaca-se a importância de ações constantes, no sentido de motivar a participação cada vez maior de mulheres em áreas tecnológicas, principalmente das meninas que frequentam escolas públicas. Muitas vezes, essas meninas esbarram com problemas diversos, como financeiros, violência física e moral tanto dentro de casa, como nas escolas ou entre amigos, e elas não têm um ambiente para conversas que estimulem o potencial inexplorado de cada uma.

Embora o projeto se apresente como uma proposta bastante interessante, esbarramos em algumas dificuldades. Primeiro, na dificuldade de compatibilização de horários junto às escolas para divulgação. Segundo, por serem carentes financeiramente, as alunas 
apresentam dificuldades para se deslocarem até a UERN a fim de participarem do projeto. E terceiro, acreditamos que o tempo de execução do projeto foi um pouco longo, o que pode ter provocado evasões. Para as próximas turmas, pretendemos mudar a programação, inserindo um maior número de atividades práticas e envolvendo computadores; condensar as ações em blocos, por exemplo, a cada 2 meses de atividades, uma nova turma para evitar a evasão; visitar um maior número de escolas e, por fim, buscar parceiros financeiros.

Para trabalhos futuros, pretendemos explorar como o projeto Maria Bonita nas Ciências se encaixa nas diretrizes que orientam a formulação e implementação das ações de Extensão Universitária, disponíveis no documento Política Nacional de Extensão Universitária [FORPROEX 2012]: interação dialógica; interdisciplinaridade e interprofissionalidade; indissociabilidade entre ensino, pesquisa e extensão; impacto na formação do estudante; e impacto e transformação social.

\section{Referências}

Alencar, A., Pinheiro, V., and Marques, A. (2019). Promovendo o conhecimento sobre mulheres na computação: experiência com o jogo de cartas computasseia no ensino de história da computação. In Anais do XIII Women in Information Technology, pages 139-143, Porto Alegre, RS, Brasil. SBC.

Andrade, R. d. O. (2019). A retomada do espaço da mulher na computação. Revista Pesquisa FAPESP. Edition 279. May.

Burge, J., Gannod, G., Doyle, M., and Davis, K. (2013). Girls on the go: a cs summer camp to attract and inspire female high school students. pages 615-620.

Ferreira, K., Barbosa, G., and Albuquerque, S. (2019). Uma iniciativa para apoiar e empoderar alunas de ensino técnico e de graduação em computação. In Anais do XIII Women in Information Technology, pages 104-108, Porto Alegre, RS, Brasil. SBC.

FORPROEX (2012). Política Nacional de Extensão Universitária., volume 7 of Coleção Extensão Universitária. Gráfica da UFRGS, Porto Alegre, RS.

Negreiros, A. (2018). Maria Bonita - Sexo, Violência e Mulheres No Cangaço. Number 1. Objetiva, Cidade da Editora.

ONU (2015). Transformando nosso mundo: A agenda 2030 para o desenvolvimento sustentável.Organização das Nações Unidas. https://nacoesunidas.org/ pos2015/agenda2030/. [Online; accessed 30-April-2020].

ONU (2020). Em dia internacional, onu diz que mulheres e meninas continuam excluídas de participação plena na ciência.Organização das Nações Unidas. https : / / news . un.org/pt/story/2020/02/1703721. [Online; accessed 30-April-2020].

Pollock, L., McCoy, K., Carberry, S., Hundigopal, N., and You, X. (2004). Increasing high school girls' self confidence and awareness of cs through a positive summer experience. SIGCSE Bull., 36(1):185-189.

SBC (2020). Programa meninas digitais. Sociedade Brasileira de Computação. http: //meninas.sbc.org.br/. [Online; accessed 30-April-2020].

UNESCO (2018). Decifrar o código: educação de meninas e mulheres em ciências, tecnologia, engenharia e matemática (STEM). Organização das Nações Unidas para a Educação, a Ciência e a Cultura. 
UNESCO (2020a). International day of women and girls in science.UNESCO - Building peace in the minds of men and women. https://en.unesco.org/events/ international-day-women-and-girls-science. [Online; accessed 30April-2020].

UNESCO (2020b). L'oréal-unesco for women in science programme.UNESCO - Building peace in the minds of men and women. https://en.unesco.org/ science-sustainable-future/women-in-science. [Online; accessed 30-April-2020].

Vachovsky, M., Wu, G., Chaturapruek, S., Russakovsky, O., Sommer, R., and Fei-Fei, L. (2016). Toward more gender diversity in cs through an artificial intelligence summer program for high school girls. pages 303-308. 